Running head: CULTURE, FACE PERCEPTION AND INTERPERSONAL CONTEXT

\title{
How different cultures look at faces depends on the interpersonal context
}

\author{
Matthias S. Gobel ${ }^{1}$ \\ Alyssa Chen ${ }^{2}$ \\ Daniel C. Richardson ${ }^{2}$ \\ 1. SAGE Center for the Study of the Mind, \\ University of California, Santa Barbara, CA 93106-9660, USA \\ 2. Department of Experimental Psychology, University College London, \\ Gower Street, WC1E 6BT, London, UK
}

Corresponding Author: Matthias S. Gobel

Email: matthias.gobel@sagecenter.ucsb.edu

Word Count: 4399 


\begin{abstract}
Culture can influence how we see and experience the world, and recent research shows that it even determines how we look at each other. Yet, most of these laboratory studies use images of faces that are deprived of any social context. In the real world, we do not only look at people's faces to perceive who they are, but also in order to signal information back to them. It is unknown, therefore, within which interpersonal contexts cultural differences in looking at faces emerge. In the current study, we manipulated one aspect of the interpersonal context of faces: whether the target face either established mutual gaze looking directly into the camera as if talking to the viewer, or averted gaze slightly to the side as if talking to another person. East Asian and Western participants viewed target face videos while their eye movements were recorded. If cultural differences are exclusively related to encoding information from others, interpersonal context should not matter. However, if cultural differences are also the result of culturally specific expectations about how to appropriately interact with another person, then cultural differences should be modulated by whether the speaker seemingly addresses the viewer or another person. In support of the second hypothesis, we only find cultural differences in looking at faces in the mutual gaze condition. We speculate that cultural norms surrounding the use of gaze as a social signal may underlie previous findings of cultural differences in face perception.
\end{abstract}

(241 words)

Keywords: Social attention; Face perception; Eye movements; Interpersonal context; Culture 


\section{How different cultures look at faces depends on the interpersonal context}

The London Piccadilly Line goes from Heathrow Airport to the centre of the city. Commuting in to work each day amongst visitors from across the world is an exercise in anthropology and cross-cultural observation. There are people who stare at the floor or a phone ignoring others, there are families who sit together muttering but do not share eye contact, there are groups that talk loudly while everyone else pretends they aren't listening, and there are people who simply stare at the many and varied people around them, as if visitors to a zoo.

One aspect of these cultural differences has been observed in the laboratory. Eye movement studies have shown that individuals from East Asia look at pictures of faces differently than those from Western cultures (Blais, Jack, Scheepers, Fiset, \& Caldara, 2008). But what accounts for these cultural differences? It has been claimed (Argyle \& Cook, 1976) and recently demonstrated experimentally (Gobel, Kim, \& Richardson, 2015; Jarick \& Kingstone, 2015) that looking at faces can have a dual function. We move our eyes to perceive different parts of a face, but in interpersonal contexts, we also look people in the eyes as a social signal, to show that we are listening to the speaker, to signal our competence, to convey attraction, and much more (Kleinke, 1986).

For cultural differences in eye movements when looking at faces, however, current experiments cannot say whether gazing behaviour changes when the speaker is looking at the viewer or is addressing another person. The faces are presented on screen with no social context or interaction, behind what has been called the 'fourth wall' of cognitive science (Risko, Richardson, \& Kingstone, 2016). It could be that people from different cultures use different strategies when perceiving and identifying a face (Caldara, Zhou, \& Miellet, 2010); 
or it could be that they have different cultural expectations about how to look at a speaker that is talking to them compared to how to look at a speaker that is talking to another person.

In this experiment, we sought to contrast these two interpersonal contexts by showing participants from East Asian and Western cultures videos of faces that differed slightly in their head and gaze direction: whether or not the speaker was looking into the camera. If cross-cultural differences are exclusively related to encoding information from others, then different gaze patterns between East Asian and Western participants should be observable across both conditions. But if cultural differences are at least in part related to culturally specific expectations about how to appropriately interact with another person, they should be modulated by whether or not the speaker makes eye contact with the viewer. To make this case, we will first review what is known about attention to faces, in and outside the laboratory, and then establish the cultural differences that are known to exist in visual attention.

\section{Social attention: Looking at others in the laboratory and in real life}

We like to look at conspecifics and especially their faces (Kingstone, 2009; Yarbus, 1965). One function of looking at another person's face is to capture information about this person (Emery, 2000; Itier, 2015). People also focus their attention to where other people are looking. Humans are able to use each other's eye movements to efficiently cooperate and communicate with each other (Frischen, Bayliss, \& Tipper, 2007; Richardson \& Gobel, 2015). For example, attending to the focus of another's attention can tell us where reward or danger is lurking in the environment. In fact, it has been suggested that the human eye with the large white sclera has been selected so that conspecifics can follow gaze more easily (Kobayashi \& Kohshima, 1997). Such ‘social attention' has a key function in various aspects of social life, facilitating interpersonal communication, successful cooperation and human interdependence (Kleinke, 1986; Richardson \& Gobel, 2015). 
In fact, visual attention in everyday life has an important communication function (Argyle \& Cook, 1976; Gobel et al., 2015; Jarick \& Kingstone, 2015). For example, magicians shift their own gaze to guide their audience's attention into a world of deception (Kuhn, Teszka, Tenaw, \& Kingstone, 2016). Interpersonal contexts determine when and where to look in various social settings, from walking across campus to sharing a meal with friends (Foulsham, Walker, \& Kingstone, 2011; Laidlaw, Foulsham, Kuhn, \& Kingstone, 2011; Wu, Bischof, \& Kingstone, 2013). While previous face perception experiments deprived participants from any interpersonal context, more recent efforts call researchers to conduct elaborate studies - inside and outside the laboratory - that allow for the pivotal role of social context to unfold (Richardson \& Gobel, 2015; Risko et al., 2016). Indeed, a better understanding of how visual attention is allocated to faces, and especially their eyes, might be improved through considering the impact of social contexts on eye movements.

\section{Cultural differences in eye movements when looking at faces}

One social context that influences how people think and behave is the culture they inhabit. Cultures describe shared and collectively constructed, habitual ways of thinking, feeling and acting within a given environment (Chiu \& Hong, 2006). Previous research has demonstrated that cultural differences exist across a wide range of cognitive phenomena (Kitayama \& Cohen, 2007). In a seminal study, for instance, Blais and colleagues (2008) tested whether the cultural background of participants would moderate how gaze is allocated during face perception. Previous research using participants from Western cultures had shown that when looking at faces, people primarily look at a triangular space between the two eyes and the mouth (Peterson \& Eckstein, 2012; Yarbus, 1965). Yet, Blais and colleagues (2008) found evidence for a distinct cultural divide in face processing: Westerners fixated more the eyes and partially the mouth, whereas East Asians fixated more the bridge of the nose. In line with these results, another study demonstrated that Japanese participants 
were mostly fixating the bridge of the nose when looking at faces (Kita et al., 2010). Moreover, children not only displayed these cultural differences in fixation patterns from early ages, but these cultural differences increased across development, suggesting that social learning is key to refining their perceptual strategies (Kelly et al., 2011).

Blais and colleagues (2008) interpreted cultural differences in face processing as differences in visual perception. They suggested that the reason why Westerners fixated the eyes and mouth more was due to their analytic perceptual style, whereas East Asians fixated the bridge of the nose more due to their holistic perceptual processing. Indeed, visual perception and attention varies across cultures (Nisbett \& Miyamoto, 2005; Nisbett, Peng, Choi, \& Norenzayan, 2001). For example, Westerners tend to utilize analytic perceptual processes with attention placed on a salient foreground object or focal point. East Asians, on the other hand, tend to engage in holistic perceptual processes, preferentially attending to the relationship between objects and the surrounding contextual information (Masuda \& Nisbett, 2001; Miyamoto, Nisbett, \& Masuda, 2006). Thus, it seems possible that cultural differences in looking at faces reflect different strategies of encoding information.

However, cultures also differ in how people interact with each other. For example, Westerners tend to express their unique self, convey what they think and signal how they feel (Kim \& Sherman, 2007; Markus \& Kitayama, 1991; Matsumoto, Takeuchi, Andayani, Kouznetsova, \& Krupp, 1998). Easterners, in stark contrast, are socialised to not stick out, control the expression of their thoughts and subdue the signalling of their feelings in order to preserve harmonious relationships with others (Kim \& Markus, 1999; Markus \& Kitayama, 1991; Matsumoto et al., 1998). Culturally specific expectations about how to appropriately interact with another person are especially pronounced when people look at one another. Westerners are comfortable with establishing mutual gaze (Argyle \& Cook, 1976), and use direct eye contact as an important tool for interpersonal communication signalling a variety 
of social information (Kleinke, 1986). East Asians, on the other hand, tend to consider excessive eye contact impolite, and thus avoid looking others directly in the eye (e.g., Sue \& Sue, 1990; Watson, 1970). Thus, previous research found that Japanese engage in less eye contact than Americans (Hawrysh \& Zaichkowsky, 1990) or Canadians (McCarthy, Lee, Itakura, \& Muir, 2006). This, in turn, seems to suggest that the interpersonal communication context might play a pivotal role as to when cultural differences in looking at faces occur.

The importance of social context for how people look at faces was recently demonstrated by Võ, Smith, Mital and Henderson (2012). In their seminal study, these authors used dynamic video stimuli that featured members of the general public with naturally varying gaze directions, bodily movements, and speech styles. They found that fixations to the eyes increased when the targets made eye contact with the camera, establishing mutual gaze. In contrast, fixations to the nose increased when the targets moved, suggesting that the nose, as the centre of the face, acted as a spatial anchor. Moreover, fixations to the mouth were amplified when targets were talking (especially when looking into the camera). Thus, the interpersonal context of the speaker directly looking at and speaking to the viewer seems to change the way viewers look at faces. In the present study, we test whether cultural differences in looking at faces would be similarly modulated by social contexts.

\section{The Current Study}

We investigated whether cultural differences in eye movements when looking at faces would differ across real-world communication contexts. We used an experimental approach to manipulate the social contexts of looking at face video-clips. Actors were filmed from two different angles: from a camera looking directly into their eyes, producing a video with mutual gaze, and one placed slightly to the side, producing a video with averted gaze. We 
measured the eye movements of Western and East Asian participants watching these videos, in order to test two competing hypotheses:

The perception hypothesis predicts that there will be consistent cultural differences in looking at faces across social contexts. Thus, across conditions, East Asian participants will fixate the bridge of the nose more, whereas Western participants will fixate the eyes more. The communication hypothesis, however, predicts that cultural differences in looking at faces will be modulated by social context. Specifically, we expected such cultural differences to arise in the mutual gaze but not the averted gaze condition.

\section{Method}

Participants. Fifty-seven individuals (45 females, $M_{\text {age }}=23.1, S D_{\text {age }}=8.10$ ) completed the study. 14 additional participants were unable to complete the study due to insufficient calibration accuracy or due to technical problems with the data recording device. 30 participants self-identified as East Asians (22 females, $M_{\text {age }}=20.8, S D_{\text {age }}=2.65$ ), whereas 27 participants self-identified as Westerners (23 females, $\left.M_{\text {age }}=25.8, S D_{\text {age }}=10.94\right) .2$ East Asian participants were ethnically Korean, while the remaining 28 were ethnically Chinese. East Asian participants were born and raised in Korea, Malaysia, Singapore, and China (including Hong Kong), and they were all university students who had, at the time of testing, lived in the United Kingdom for less than three years. The Western participants consisted of 24 British, 1 Icelandic, 1 German, and 1 Bulgarian. All participants were fluent in English, and had normal or corrected vision. Participants were awarded either course credits or monetary compensation for their participation. Approval for the study was obtained from the UCL Experimental Psychology Research Ethics Committee, and informed consent was obtained from all participants prior to the study.

Design. A 3 (Region of Interest: eyes versus nose versus mouth) x 2 (Culture: Western versus East Asian) x 2 (Interpersonal Context: mutual gaze versus averted gaze) 
mixed design was used for this experiment, with culture and interpersonal context as the between-subjects variables, and the Regions of Interest (ROIs) as the within-subjects variable. The dependent variable was the proportion of fixation duration allocated to ROIs.

Apparatus. Participants were seated approximately $65 \mathrm{~cm}$ in front of a 24 " LCD with a resolution of $1680 \times 1050$ pixels. A SMI 250 remote eye tracker was positioned at the base of the monitor sampling gaze positions at a frequency of $250 \mathrm{~Hz}$ and with an accuracy of approximately 0.5 degrees.

Stimuli. Eight different video stimuli were created for the purpose of this study. Each video featured one of four actors (1 East Asian male, 1 East Asian female, 1 Western male, 1 Western female). Actors were recorded while talking about a topic unrelated to identity (i.e., tourist sights in London). This topic was chosen as it was a typical conversation subject that would also minimise any chance of targets disclosing personal information that might alter gazing behaviour. Actors were instructed to remain as still as possible with neutral facial expressions.

We recorded the actors from two angles simultaneously, creating two videos with identical content. To create the mutual gaze condition, a first camera was placed directly in front of subjects, and they were instructed to focus their gaze on this camera. To create the averted gaze condition, a second camera was placed approximately 20 centimetres to the right of the first camera, and subjects were instructed to not focus their gaze on that camera. Thus, both cameras recorded the same content at the same time, and video-clips were nearly identical in low-level visual features.

The video-clip resolution was $640 \times 480$ pixels, and target faces presented on screen subtended 34 x 26 degrees of visual angle. Each video was 20 seconds in length, featuring targets silent for the first couple of seconds, then describing their favourite tourist attractions in London for the remaining time. 
Procedure. Participants completed the study individually in the controlled environment of a testing cubicle. After giving informed consent, participants completed a short questionnaire about their demographic background. They then read a brief instruction sheet that explained the alleged purpose of our study. We told participants that the study was investigating peoples' physiological responses to London and that the eye tracker measured pupil dilation rather than eye movements. The purpose of this deception was to keep participants naïve to the true aims of the experiment, and to avoid that task demands would change naturally occurring gazing behaviour. Moreover, it was important to us that participants would freely view the video-clips similar to real life, where looking at faces could potentially have a multitude of functions.

To start the experiment, participants underwent a 9-point eye tracker calibration procedure. Participants were then randomly assigned to watch either 4 video-clips with mutual gaze or 4 video-clips with averted gaze. They watched the four corresponding video stimuli in random order. Each trial showed a screen with the video number ( 1 to 4 ) for 1.5 seconds, followed by a screen with a central fixation cross for 1.5 seconds, and the video clip for 20 seconds. Overall, the study took an average of 10 minutes to complete. 

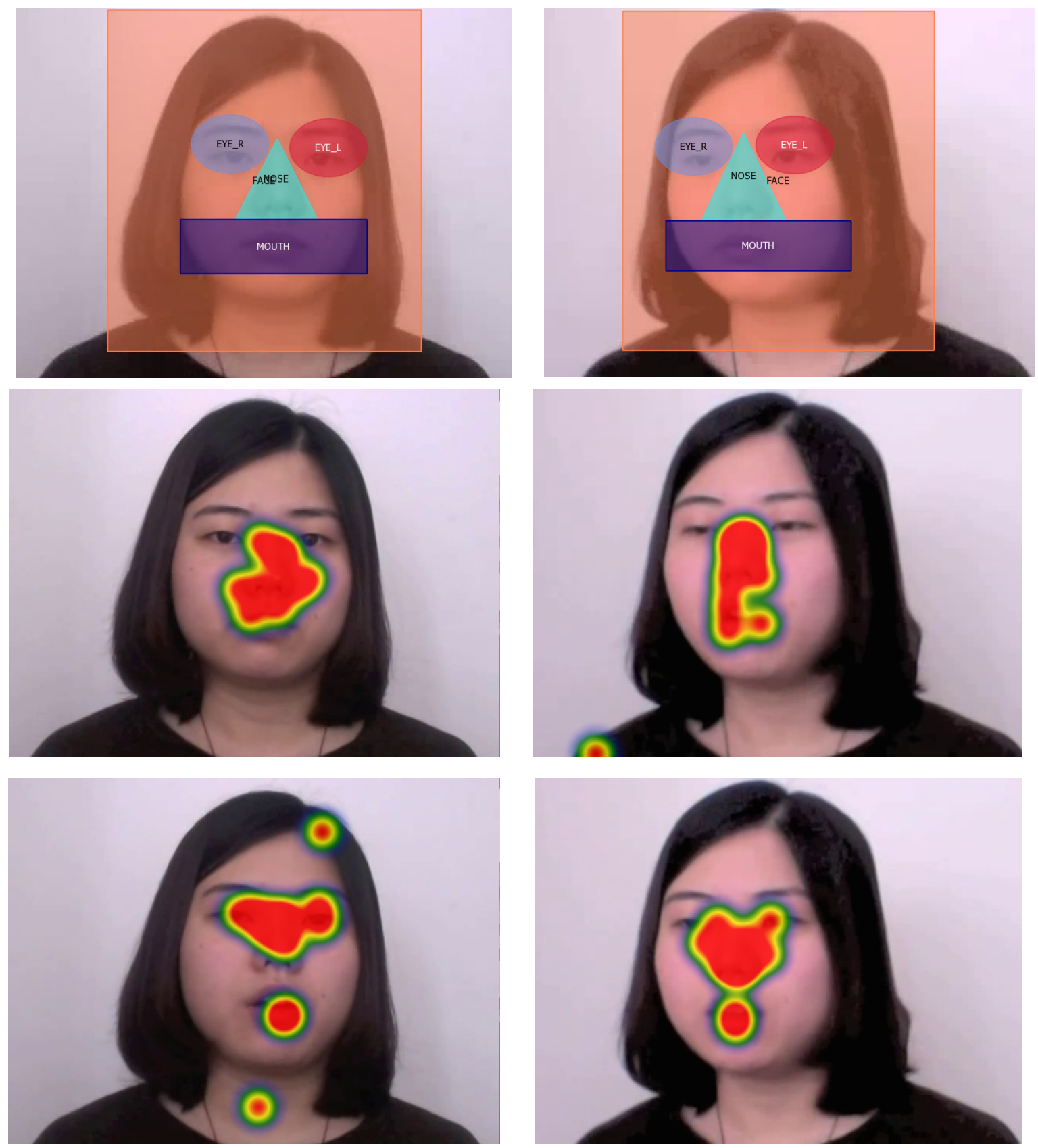

Figure 1. Top row: Regions of Interest (ROI) coded for direct (left) and averted (right) gaze condition. Centre row: Average heat map (with red colour indicating more fixations) across all East Asian participants' fixations to faces depicting direct (left) and averted (right) gaze. Bottom row: Average heat map (with red colour indicating more fixations) across all Western participants' fixations to faces depicting direct (left) and averted (right) gaze. 


\section{Results}

\section{Analysis strategy}

We drew dynamic and non-overlapping regions of interest (ROIs) around each eye, the nose, the mouth, and the overall face region for each of the eight video stimuli independently (see Figure 1 for one example). Specifically, each eye was coded with an oval that included the eyebrows. The two eye regions were summed together to create a general eye region of interest. The nose was coded with a triangle that ended between the eyebrows, and the mouth was coded with a rectangle that started directly below the nose region and ended approximately halfway down the chin. The overall face region was coded with a rectangle. We based these regions on previous work investigating social attention to videoclips (e.g., Võ et al., 2012).

Fixation durations were detected using the software BeGaze 3.3 (SensoMotoric Instruments, Teltow, Germany). Consistent with previous work on social attention to video clips (Foulsham, Cheng, Tracy, Henrich, \& Kingstone, 2010; Võ et al., 2012), we then computed the proportion of fixation duration to eyes, nose and mouth out of the overall fixation durations to the face region.

\section{Eye movements}

We found that the interpersonal communication context of looking at faces modulated cultural differences in fixation durations. A mixed-design ANOVA revealed the predicted three-way interaction of ROI by Culture by Interpersonal Context, $F(2,106)=3.79, p=.026$, $\eta_{\mathrm{p}}{ }^{2}=0.067$. The pattern of results is shown in Figure 2 .

We found a significant main effect of ROI, $F(2,106)=21.59, p<.001, \eta_{\mathrm{p}}{ }^{2}=0.289$, such that targets' noses were overall fixated the most $(M=0.42, S E M=0.03)$, and targets' mouth $(M=0.25, S E M=0.03)$ were fixated more than targets' eyes $(M=0.15, S E M=0.02)$. Moreover, we observed a significant ROI by culture interaction, $F(2,106)=3.74, p=.027$, 
$\eta_{\mathrm{p}}{ }^{2}=0.066$, which was further qualified by interpersonal context. To interpret this 3-way interaction, we analysed cultural differences in looking at faces for each of the interpersonal contexts separately.
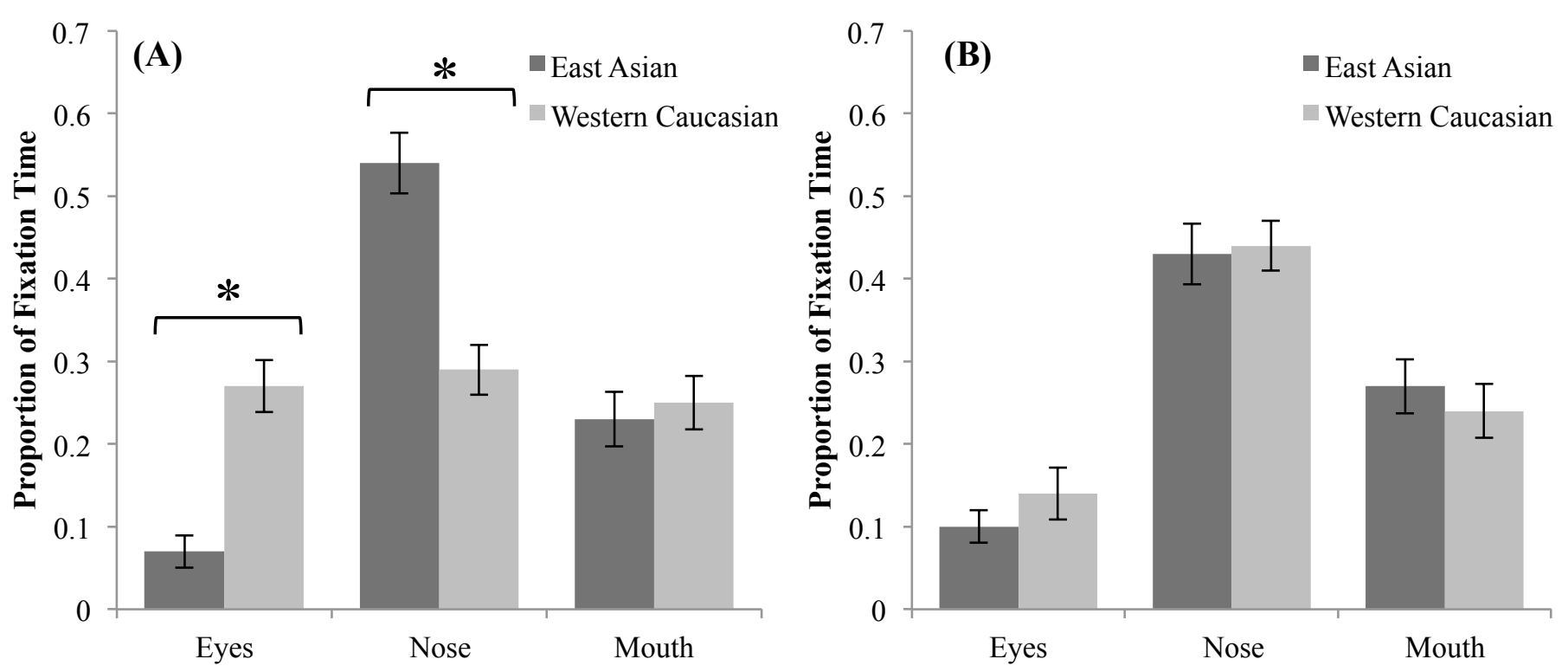

Figure 2. Means and standard errors for the proportions of fixation time for each ROI. (A) Direct gaze condition. (B) Averted gaze condition. Significant differences between observers from different cultures are reported above the bars $(* p<.05)$. Error bars indicate standard errors.

When participants viewed faces with mutual gaze, cultural differences in fixation duration emerged. Consistent with predictions, we found a significant ROI by culture interaction, $F(2,48)=4.76, p=.013, \eta_{\mathrm{p}}^{2}=0.166$. Planned comparisons indicated that Western participants fixated the eyes more $(M=0.27, S E M=0.05)$ than East Asians participants $(M=0.07, S E M=0.05), p=.012$. In contrast, East Asians participants fixated the bridge of the nose more $(M=0.54, S E M=0.07)$ than Western participants $(M=0.28$, $S E M=0.07), p=.012$. There were no cultural differences in fixation durations to the mouth (East Asians: $M=0.23, S E M=0.07$; Westerners: $M=0.25, S E M=0.07, p=.839$ ). 
When participants viewed faces with averted gaze, however, no cultural differences in looking at faces were observed. A ROI by Culture mixed ANOVA did not yield a significant culture by ROI interaction, $F(2,58)=0.188, p=.829, \eta_{\mathrm{p}}{ }^{2}=0.006$.

Moreover, post-hoc comparisons within cultures showed no ROI by interpersonal context interaction for East Asian participants, $F(2,56)=1.157, p=.322, \eta_{\mathrm{p}}{ }^{2}=0.04$, but a marginal ROI by interpersonal context interaction for Western participants, $F(2,50)=2.910$, $p=.064, \eta_{\mathrm{p}}{ }^{2}=0.104$. Westerners appeared to somewhat fixate the eyes more (Bonferronicorrected $p=.053$ ) but the nose less (Bonferroni-corrected $p=.065$ ), in the mutual but not the averted gaze condition.

When entering the culture and the gender of the target faces as additional factors into our mixed-design ANOVA, there was no effect of target culture, $F(1,53)=1.94, p=.17, \eta_{\mathrm{p}}{ }^{2}$ $=0.035$, and the effect of target gender was marginal, $F(1,53)=3.43, p=.07, \eta_{\mathrm{p}}{ }^{2}=0.061$. Neither target culture, nor target gender qualified the predicted 3-way interaction of ROI by Culture by Interaction Context, which remained significant, $F(2,106)=3.64, p=.03, \eta_{\mathrm{p}}{ }^{2}=$ 0.064 , suggesting that the observed effects were not restricted to specific identities of the target stimulus.

Overall, there was no main effect of participants' culture, $F(1,48)=0.00, p=.984$, $\eta_{\mathrm{p}}{ }^{2}=0.000$, neither was there a main effect of participants' gender, $F(1,48)=0.20, p=.654$, $\eta_{\mathrm{p}}{ }^{2}=0.004$, nor was there a main effect of participants' age, $F(1,48)=1.89, p=.175, \eta_{\mathrm{p}}{ }^{2}=$ 0.038 .

\section{Discussion}

How different cultures look at faces is modulated by interpersonal communication contexts. When participants viewed a video depicting a target face that looked directly into the camera and therefore established mutual gaze, similar to when a speaker directly addresses the viewer, cultural differences emerged consistent with patterns documented in 
previous research (Blais et al., 2008; Caldara et al., 2010; Kelly et al., 2011). Specifically, while Western participants fixated the eyes more than East Asian participants, East Asian participants fixated the bridge of the nose more than Western participants. However, when participants viewed an almost identical video depicting the same target face but now looking past the camera, similar to when a speaker addresses another person but not the viewer, no cultural differences emerged.

One possible interpretation of our findings is that in near-naturalistic environments, we look at other people's faces not only to encode information from them but also to communicate with them. Previous research has shown that when looking at faces in social contexts, we sometimes prolong direct eye contact. Gobel and colleagues (2015) demonstrated, for example, that believing a lower ranking face is looking back at the viewer increased the viewer's gaze duration to targets' eyes, perhaps to signal their superior social rank. Similarly, Jarick and Kingstone (2015) found that after playing competitive rather than cooperative games with others, participants looked at their opponents' eyes for longer periods, presumably because they were signalling their competitiveness.

Not looking at faces or averting gaze can be a subtle but a just as meaningful signal of communication intentions. Indeed, people sometimes tend to not look at strangers' faces, for instance when walking past them on campus (Foulsham et al., 2011), when strangers answer their phone (Laidlaw, Rothwell, \& Kingstone, 2016), or when another person is eating (Wu et al., 2013). Importantly, to the extent that cultures have differing expectations about nonverbal behaviour during interpersonal interaction (Matsumoto, 2006), culturally specific norms about the appropriateness of eye contact might help explain our findings.

For example, within the Japanese cultural context, and perhaps across East Asia, avoiding eye contact is a signal of respect (e.g., Sue \& Sue, 1990). One study found that Japanese managers made less eye contact than their American colleagues (Hawrysh \& 
Zaichkowsky, 1990), and Japanese maintained less eye contact than Canadian interviewees when answering questions of an interviewer (McCarthy et al., 2006). Western cultures, on the other hand, value direct eye contact to signal interest in others, attentiveness and respect (Argyle \& Cook, 1976; Kleinke, 1986). For example, interviewers are evaluated as more attentive when establishing mutual gaze with interviewees (Ellsworth \& Carlsmith, 1968; Kleinke, Staneski, \& Berger, 1975), and people are generally perceived as more attentive when gazing during social encounters (Kleinke \& Pohlen, 1971; Kleinke \& Singer, 1979). Thus, participants from Western cultures look at faces with direct gaze longer (Senju \& Johnson, 2009), and their cognitive (Hood, Macrae, Cole-Davies, \& Dias, 2003), physiological and neural responses (Akechi et al., 2013; Hietanen, Leppänen, Peltola, Linnaaho, \& Ruuhiala, 2008) to faces with direct gaze are amplified.

Consequently, we propose that participants might have been signalling their culturally specific communication norms when direct eye contact was made. Consistent with the interpretation that avoiding direct eye contact signals respect in East Asian cultures and that engaging in direct eye contact signals interest in Western cultures, we found that East Asian more than Western participants fixated the bridge of the nose, whereas Western more than East Asian participants fixated the eyes. Importantly, these cultural differences only emerged in the mutual gaze but not in the averted gaze condition, presumably because only in the mutual gaze condition, participants construed the situation as being akin to an interaction with the speaker who looked directly at them.

Alternatively, it is also possible that cultural differences in encoding visual information from the face underlie our findings, as previous research investigating the recognition of emotional expressions across cultures might suggest. For example, cultures differ in their expectations regarding what information should be attended to in the face (Jack, Blais, Scheepers, Schyns, \& Caldara, 2009; Yuki, Maddux, \& Masuda, 2007). In part 
this might be due to the fact that emotional expressions are not universal (Jack, Garrod, Yu, Caldara, \& Schyns, 2012). Perhaps visual attention was strategically employed to encode the culturally relevant information regarding emotional expressions, since cultures have been shown to differ in the facial features that are especially diagnostic of specific emotions (Jack, Caldara, \& Schyns, 2012).

Because we had instructed our actors to talk about topics unrelated to identity using their natural voice without moving much, we believe it is unlikely that our stimuli depicted strong emotional expressions. Moreover, any emotional expression should have been visible more or less equally in the mutual gaze and the averted gaze condition. Thus, if cultural differences in the recognition of emotional expression explain our findings, then the interpersonal context of communicating them to the viewer or to another person seems still to be driving the observed differences between experimental conditions. Future research is needed to better understand the role that the recognition of emotional expressions can play across cultures in real-life interpersonal contexts.

The goal of the present research was to discover if cultures looked at faces differently depending on the social context, and we did not have specific hypotheses about the direction of within-culture differences. It seemed possible that Westerners would increase their attention to the eyes in the mutual gaze relative to the averted gaze condition, and it also seemed possible that Easterners would reduce their attention to the eyes in the mutual gaze relative to the averted gaze condition. Post-hoc analyses yielded evidence consistent with the former rather than the latter within-culture differences. Yet, we caution that these post-hoc findings should be independently confirmed in future studies. Such replication would also benefit from larger samples and the inclusion of an East Asian cultural sample from East Asia, both limitations to the current design. 
It is important to note that our experiment employed naturalistic video-clips of target faces. Of course, looking at a video-clip can yield different eye movements than looking at real people (e.g., Foulsham et al., 2011; Kuhn et al., 2016; Laidlaw et al., 2011; Pönkänen, Alhoniemi, Leppänen, \& Hietanen, 2011). At the same time, using dynamic video-clips provides more real-life social context compared to the use of unanimated photographs (e.g., Blais et al., 2008; Jack et al., 2009; Yuki et al., 2007), and we believe it is an important finding that minimal changes in social context yield quite dramatic changes in relation to cultural differences in looking at faces. When the target face was looking directly into the camera as if talking to the viewer, but not when the target face was looking slightly past the camera as if talking to another person, cultural differences in looking at faces emerged.

It seems that we might all look at a picture of faces on the Piccadilly line in the same way, but if we were sat on the train amongst the travellers, our cultural background would shape our gazing behaviour. 


\section{References}

Akechi, H., Senju, A., Uibo, H., Kikuchi, Y., Hasegawa, T., \& Hietanen, J. K. (2013). Attention to Eye Contact in the West and East: Autonomic Responses and Evaluative Ratings. PLoS ONE, 8(3), e59312. http://doi.org/10.1371/journal.pone.0059312

Argyle, M., \& Cook, M. (1976). Gaze and mutual gaze. Cambridge, UK: Cambridge University Press.

Blais, C., Jack, R. E., Scheepers, C., Fiset, D., \& Caldara, R. (2008). Culture shapes how we look at faces. PloS One, 3(8), e3022. http://doi.org/10.1371/journal.pone.0003022

Caldara, R., Zhou, X., \& Miellet, S. (2010). Putting Culture Under the "Spotlight" Reveals Universal Information Use for Face Recognition. PLoS ONE, 5(3), e9708. http://doi.org/10.1371/journal.pone.0009708

Chiu, C. Y., \& Hong, Y.-Y. (2006). Social Psychology of Culture. New York, NY: Taylor \& Francis.

Ellsworth, P. C., \& Carlsmith, J. M. (1968). Effects of eye contact and verbal content on affective response to a dyadic interaction. Journal of Personality and Social Psychology, 10(1), 15-20. http://doi.org/10.1037/h0026385

Emery, N. J. (2000). The eyes have it: the neuroethology, function and evolution of social gaze. Neuroscience and Biobehavioral Reviews, 24(6), 581-604. http://doi.org/10.1016/S0149-7634(00)00025-7

Foulsham, T., Cheng, J. T., Tracy, J. L., Henrich, J., \& Kingstone, A. (2010). Gaze allocation in a dynamic situation: effects of social status and speaking. Cognition, 117(3), 319-31. http://doi.org/10.1016/j.cognition.2010.09.003

Foulsham, T., Walker, E., \& Kingstone, A. (2011). The where, what and when of gaze allocation in the lab and the natural environment. Vision Research, 51(17), 1920-31. 
http://doi.org/10.1016/j.visres.2011.07.002

Frischen, A., Bayliss, A. P., \& Tipper, S. P. (2007). Gaze cueing of attention: visual attention, social cognition, and individual differences. Psychological Bulletin, 133(4), 694-724. http://doi.org/10.1037/0033-2909.133.4.694

Gobel, M. S., Kim, H. S., \& Richardson, D. C. (2015). The Dual Function of Social Gaze. Cognition, 136, 359-364. http://doi.org/10.1016/j.cognition.2014.11.040

Hawrysh, B. M., \& Zaichkowsky, J. L. (1990). Cultural Approaches to Negotiations: Understanding the Japanese. International Marketing Review, 7(2), 28-43. http://doi.org/10.1108/EUM0000000000626

Hietanen, J. K., Leppänen, J. M., Peltola, M. J., Linna-aho, K., \& Ruuhiala, H. J. (2008). Seeing direct and averted gaze activates the approach-avoidance motivational brain systems. Neuropsychologia, 46(9), 2423-2430. http://doi.org/10.1016/j.neuropsychologia.2008.02.029

Hood, B. M., Macrae, C. N., Cole-Davies, V., \& Dias, M. (2003). Eye remember you: the effects of gaze direction on face recognition in children and adults. Developmental Science, 6(1), 67-71. http://doi.org/10.1111/1467-7687.00256

Itier, R. J. (2015). Attention to Eyes in Face Perception. In J. M. Fawcett, E. F. Risko, \& A. Kingstone (Eds.), The Handbook of Attention (pp. 369-388). Cambridge, MA: The MIT Press.

Jack, R. E., Blais, C., Scheepers, C., Schyns, P. G., \& Caldara, R. (2009). Cultural Confusions Show that Facial Expressions Are Not Universal. Current Biology, 19(18), 1543-1548. http://doi.org/10.1016/j.cub.2009.07.051

Jack, R. E., Caldara, R., \& Schyns, P. G. (2012). Internal Representations Reveal Cultural Diversity in Expectations of Facial Expressions of Emotion. Journal of Experimental Psychology: General, 141(1), 19-25. http://doi.org/10.1037/a0023463 
Jack, R. E., Garrod, O. G. B., Yu, H., Caldara, R., \& Schyns, P. G. (2012). Facial expressions of emotion are not culturally universal. Proceedings of the National Academy of Sciences of the United States of America, 109(19), 7241-4. http://doi.org/10.1073/pnas.1200155109

Jarick, M., \& Kingstone, A. (2015). The duality of gaze: eyes extract and signal social information during sustained cooperative and competitive dyadic gaze. Frontiers in Psychology, 6(September), 1423. http://doi.org/10.3389/fpsyg.2015.01423

Kelly, D. J., Liu, S., Rodger, H., Miellet, S., Ge, L., \& Caldara, R. (2011). Developing cultural differences in face processing. Developmental Science, 14(5), 1176-84. http://doi.org/10.1111/j.1467-7687.2011.01067.x

Kim, H. S., \& Markus, H. R. (1999). Deviance or uniqueness, harmony or conformity? A cultural analysis. Journal of Personality and Social Psychology, 77(4), 785-800. http://doi.org/10.1037//0022-3514.77.4.785

Kim, H. S., \& Sherman, D. K. (2007). “Express Yourself”: Culture and the Effect of SelfExpression on Choice. Journal of Personality and Social Psychology, 92(1), 1-11. http://doi.org/10.1037/0022-3514.92.1.1

Kingstone, A. (2009). Taking a real look at social attention. Current Opinion in Neurobiology, 19(1), 52-6. http://doi.org/10.1016/j.conb.2009.05.004

Kita, Y., Gunji, A., Sakihara, K., Inagaki, M., Kaga, M., Nakagawa, E., \& Hosokawa, T. (2010). Scanning strategies do not modulate face identification: Eye-tracking and nearinfrared spectroscopy study. PLOS ONE, 5(6), e11050. http://doi.org/10.1371/journal.pone.0011050

Kitayama, S., \& Cohen, D. (2007). Handbook of Cultural Psychology. New York, NY: The Guilford Press.

Kleinke, C. L. (1986). Gaze and eye contact: A research review. Psychological Bulletin, 
100(1), 78-100. http://doi.org/10.1037/0033-2909.100.1.78

Kleinke, C. L., \& Pohlen, P. D. (1971). Affective and emotional responses as a function of other person's gaze and cooperativeness in a two-person game. Journal of Personality and Social Psychology, 17(3), 308-313. http://doi.org/10.1037/h0030600

Kleinke, C. L., \& Singer, D. A. (1979). Influence of Gaze on Compliance with Demanding and Conciliatory Requests in a Field Setting. Personality and Social Psychology Bulletin, 5(3), 386-390.

Kleinke, C. L., Staneski, R. A., \& Berger, D. E. (1975). Evaluation of an interviewer as a function of interviewer gaze, reinforcement of subject gaze, and interviewer attractiveness. Journal of Personality and Social Psychology, 31(1), 115-22. http://doi.org/10.1037/h0076244

Kobayashi, H., \& Kohshima, S. (1997). Unique morphology of the human eye. Nature, 387(1992), 767-768.

Kuhn, G., Teszka, R., Tenaw, N., \& Kingstone, A. (2016). Don’t be fooled! Attentional responses to social cues in a face-to-face and video magic trick reveals greater top-down control for overt than covert attention. Cognition, 146, 136-142. http://doi.org/10.1016/j.cognition.2015.08.005

Laidlaw, K. E. W., Foulsham, T., Kuhn, G., \& Kingstone, A. (2011). Potential social interactions are important to social attention. Proceedings of the National Academy of Sciences of the United States of America, 108(14), 5548-53.

http://doi.org/10.1073/pnas.1017022108

Laidlaw, K. E. W., Rothwell, A., \& Kingstone, A. (2016). Camouflaged attention: Covert attention is critical to social communication in natural settings. Evolution and Human Behavior, 37(6), 449-455. http://doi.org/10.1016/j.evolhumbehav.2016.04.004

Markus, H. R., \& Kitayama, S. (1991). Culture and the self: Implications for cognition, 
emotion, and motivation. Psychological Review, 98(2), 224-253. http://doi.org/10.1037//0033-295X.98.2.224

Masuda, T., \& Nisbett, R. E. (2001). Attending holistically versus analytically: Comparing the context sensitivity of Japanese and Americans. Journal of Personality and Social Psychology, 81(5), 922-934. http://doi.org/10.1037//0022-3514.81.5.922

Matsumoto, D. (2006). Culture and nonverbal behavior. In V. Manusov \& M. L. Patterson (Eds.), The SAGE Handbook of Nonverbal Communication (pp. 219-236). Thousand Oaks, CA: SAGE Publications. http://doi.org/10.4135/9781412976152.n12

Matsumoto, D., Takeuchi, S., Andayani, S., Kouznetsova, N., \& Krupp, D. (1998). The Contribution of Individualism vs. Collectivism to Cross-national Differences in Display Rules. Asian Journal Of Social Psychology, 1(2), 147-165. http://doi.org/10.1111/1467839X.00010

McCarthy, A., Lee, K., Itakura, S., \& Muir, D. W. (2006). Cultural display rules drive eye gaze during thinking. Journal of Cross-Cultural Psychology, 37(6), 717-722. http://doi.org/10.1177/0022022106292079

Miyamoto, Y., Nisbett, R. E., \& Masuda, T. (2006). Culture and the physical environment. Holistic versus analytic perceptual affordances. Psychological Science, 17(2), 113-9. http://doi.org/10.1111/j.1467-9280.2006.01673.x

Nisbett, R. E., \& Miyamoto, Y. (2005). The influence of culture: holistic versus analytic perception. Trends in Cognitive Sciences, 9(10), 467-73. http://doi.org/10.1016/j.tics.2005.08.004

Nisbett, R. E., Peng, K., Choi, I., \& Norenzayan, A. (2001). Culture and systems of thought: Holistic versus analytic cognition. Psychological Review, 108(2), 291-310. http://doi.org/10.1037/0033-295X.108.2.291

Peterson, M. F., \& Eckstein, M. P. (2012). Looking just below the eyes is optimal across face 
recognition tasks. Proceedings of the National Academy of Sciences of the United States of America, 109(48), E3314-23. http://doi.org/10.1073/pnas.1214269109

Pönkänen, L. M., Alhoniemi, A., Leppänen, J. M., \& Hietanen, J. K. (2011). Does it make a difference if I have an eye contact with you or with your picture? An ERP study. Social Cognitive and Affective Neuroscience, 6(4), 486-94. http://doi.org/10.1093/scan/nsq068

Richardson, D. C., \& Gobel, M. S. (2015). Social Attention. In J. M. Fawcett, E. F. Risko, \& A. Kingstone (Eds.), The Handbook of Attention (pp. 349-367). Cambridge, MA: The MIT Press.

Risko, E. F., Richardson, D. C., \& Kingstone, A. (2016). Breaking the Fourth Wall of Cognitive Science: Real-World Social Attention and the Dual Function of Gaze. Current Directions in Psychological Science, 25(1), 70-74.

http://doi.org/10.1177/0963721415617806

Senju, A., \& Johnson, M. H. (2009). The eye contact effect: mechanisms and development. Trends in Cognitive Sciences, 13(3), 127-134. http://doi.org/10.1016/j.tics.2008.11.009

Sue, D. W., \& Sue, D. (1990). Counseling the culturally different: Theory and practice. New York, NY: Wiley.

Võ, M. L.-H., Smith, T. J., Mital, P. K., \& Henderson, J. M. (2012). Do the eyes really have it? Dynamic allocation of attention when viewing moving faces. Journal of Vision, 12(13), 1-14. http://doi.org/10.1167/12.13.3.Introduction

Watson, O. M. (1970). Proxemic behavior: A cross-cultural study. The Hague, The Netherlands: Mouton.

Wu, D. W.-L., Bischof, W. F., \& Kingstone, A. (2013). Looking while eating: the importance of social context to social attention. Scientific Reports, 3, 2356. http://doi.org/10.1038/srep02356

Yarbus, A. L. (1965). Eye Movements and Vision. New York, NY: Plenum Press. 
Yuki, M., Maddux, W. W., \& Masuda, T. (2007). Are the windows to the soul the same in the East and West? Cultural differences in using the eyes and mouth as cues to recognize emotions in Japan and the United States. Journal of Experimental Social Psychology, 43(2), 303-311. http://doi.org/10.1016/j.jesp.2006.02.004 